\title{
Compact planar ultrawideband MIMO antenna for wireless applications
}

\author{
P. Pavithra, A. Sriram, K. Kalimuthu
}

Department of Electronics and Communication Engineering, SRM Institute of Science and Technology, India

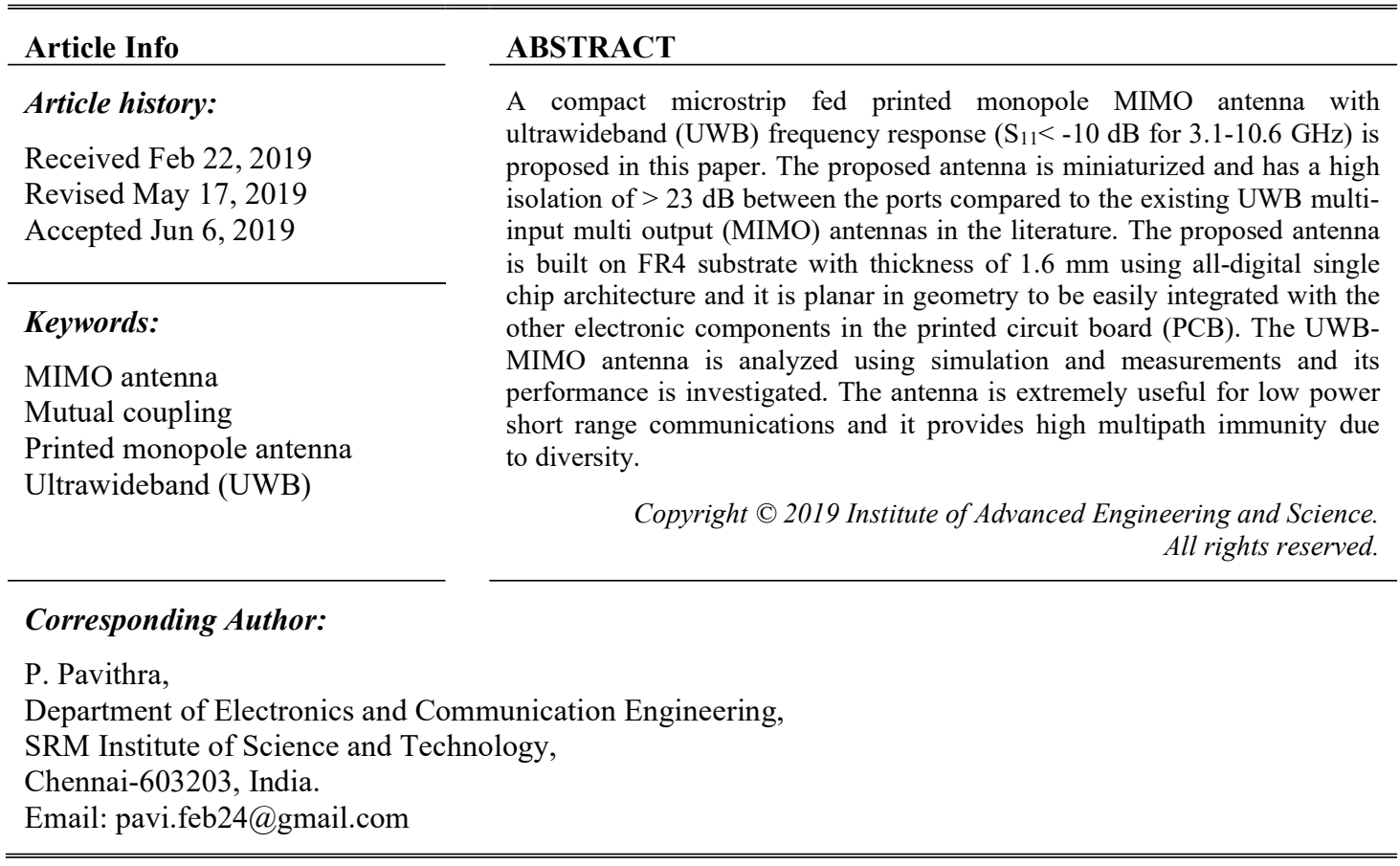

\section{INTRODUCTION}

Ultra-wideband (UWB) technologies have widely drawn considerable attention due to the several advantages for communications and sensing applications due to the properties of low-power consumption, high data rate, robustness to the multipath environment, relatively low complexity and high time-domain resolution. UWB antennas cover the frequency range of $3.1 \mathrm{GHz}$ to $10.6 \mathrm{GHz}$ which is mainly assigned for the UWB indoor communication applications. Currently, there is a huge demand in increasing the channel capacity. Hence, the two or more, multiple antennas in a single terminal can provide higher data rate which increases the channel capacity without sacrificing the requirement of additional power and frequency bands.

MIMO, Multiple-Input Multiple-Output systems are enriched withmultiple antennas, which can be used as both in transmitter as well as in receiver mode. These multiple antennas have the advantages of higher data rate which in turn enhances the channelcapacity, greater reliability of the system without any extra power or bandwidth. Since, multiple antennas occupy the same arrayof antenna structure, less spacing would be placed between them, and hence mutual coupling isincreased. Hence, high port isolation is recommended to reduce the losses.

The combination of UWB technology with multi-input multi output (MIMO) is proposed in this paper. This system increases the channel capacity for several users to access several services at the same time. It also overcomes the disadvantage of multipath fading in which conventional UWB technologies are facing. This paper gives an effective solution for the limitation of short range communication which require low power consumption devices. But in MIMO technology, several factors of antenna are to be considered such as size, isolation and gain etc.

Several techniques have been introduced such as slits [1] to enhance the impedance matching. A2 $\times 1$ UWB MIMO antenna is designed in [2] with only limited bandwidth $(3-6 \mathrm{GHz})$ which does not meet 
the FCC specifications and there are many parameters that influence the isolation and VSWR. Whereas, some of the antennas have complex geometry [3] to achieve UWB response. In order to reduce mutual coupling between MIMO antennas ,many configurations and structures have been implemented.Protruded stubs with two element MIMO are introducedin [4] to reduce the wideband mutual coupling between the radiators, the space is not used effectivelywhich results in larger size of antenna.Although many neutralization lines are implemented in [5] to reduce the wideband mutual coupling between the radiators, theisolaton reported is veryless at higher frequencies. The UWB band is covered thoughwrench shaped structures with slots [6]. In [7], a diversity MIMO antenna has been desiged in which protrudedstubs that are employed for the port isolation between the antenna elements to cover theentire UWB spectrum. In [8], a 2-port compact MIMO antenna using asymmetric coplanarstrip feeding configuration has been design with the structure of slots between the monopole andthe ground plane for the achievement of high port isolation of $20 \mathrm{~dB}$. The Isolation of $<-15 \mathrm{~dB}$ hasbeen achievced by designing defected ground plane and the introduction of the slits in the patchof the antenna as in [9]. In [10], isolation is not very high even without decoupling structures. Though various slots have been introduced in [11], lower UWB range is not covered. A highly compact single element antenna is designed for UWB applications in [12] which cannot be used for MIMO applications. MIMO antennas in $[13,14]$ occupy a larger board space to radiate a particular frequency range of 2.41-2.46 GHz and 2.2-2.9 GHz respectively.

In summary, the size of the existing antennas is vey large when compared with proposed fourelement MIMO antenna. This paper addresses the issues of size, complexity and isolationof UWB MIMO antenna.

\section{ATENNA DESIGN}

\subsection{Conventional single element UWB antenna design}

The geometry of a single element UWB antenna and detailed design parameters are shown in Figure 1 and Table 1 respectively. The proposed monopole antenna is printed on the FR4 - epoxy substrate with the thickness of $1.6 \mathrm{~mm}$ and dielectric loss tangent of 0.02 . The total volume of the antenna is $40 \times 40 \times$ $1.6 \mathrm{~mm}^{3}$. A circular radiating patch is etched on the front side of the substrate and a partial ground plane is present on the back side.

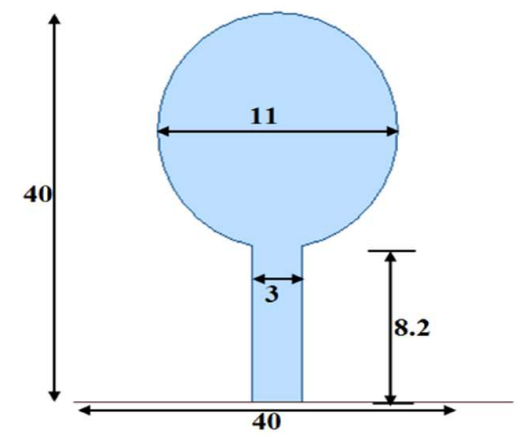

(a)

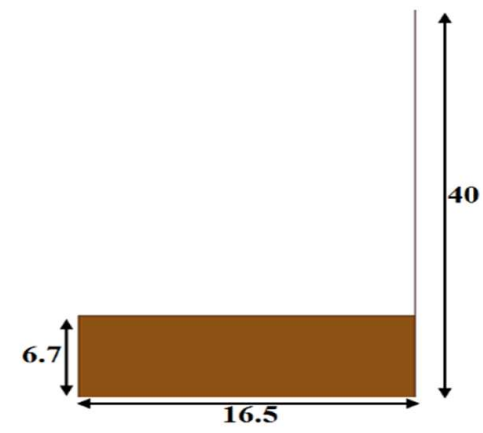

(b)

Figure 1. (a) Top layer of single element antenna and (b) Bottom layer of single element antenna (all dimensions are in $\mathrm{mm}$ )

Table 1. Dimensions of the single element UWB monopole antenna

\begin{tabular}{|c|c|c|c|c|c|}
\hline \multirow{2}{*}{$\begin{array}{l}\text { Sl. } \\
\text { No. }\end{array}$} & \multirow{2}{*}{ Structure } & \multirow{2}{*}{ Material } & \multicolumn{3}{|c|}{ Size $(\mathrm{mm})$} \\
\hline & & & $\mathrm{X}$ & $\mathrm{Y}$ & $\mathrm{Z}$ \\
\hline 1 & Substrate & FR4 - epoxy & 40 & 40 & 1.6 \\
\hline 2 & Patch & Copper & 5.5 (radius) & - & 0.035 \\
\hline 3 & Feedline & Copper & 8.2 & 3 & 0.035 \\
\hline 4 & Ground & Copper & 16.5 & 6.7 & 0.035 \\
\hline
\end{tabular}




\subsection{Four element UWB MIMO antenna}

Figure 2 depicts the geometry of the four element UWB MIMO antenna. The microstrip fed antenna is matched at $50 \Omega$ impedance which gives radiation with high reliability and impedance matching. The principle antenna element is considered as a circular quarter wave monopole with the edge to feed gap distance of $1.5 \mathrm{~mm}$. This feed gap determines the impedance bandwidth of the antenna. The antenna elements are spatially constructed with high intrinsic isolation without any additional filtering requirements and that allows easy extension of number of elements in an array. The absence of decoupling circuit or isolating structures gives the compact size of $40 \times 40 \times 1.6 \mathrm{~mm}^{3}$. This is the most compact four element MIMO antenna realized till date.

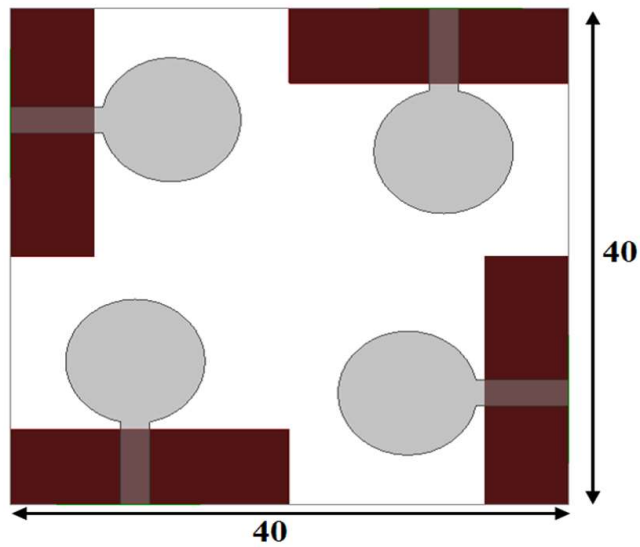

Figure 2. Four element UWB MIMO antenna (all dimensions are in $\mathrm{mm}$ )

\section{RESULTS AND DISCUSSION}

\subsection{Return loss}

Initially, single element UWB antenna is simulated and its performance in terms of return loss andgain are analyzed. Later, four element UWB MIMO antenna is implemented and the antenna's performances are re-analyzed. The simulated results of the antenna is illustrated by the excitation given at port 1 while the other ports are matched with $50 \Omega$ load. The proposed antenna has $<-10 \mathrm{~dB}$ impedance bandwidth over the operating band. The simulated result of return loss plot of single element UWB antenna and four element UWB MIMO antenna is compared in Figure 3.

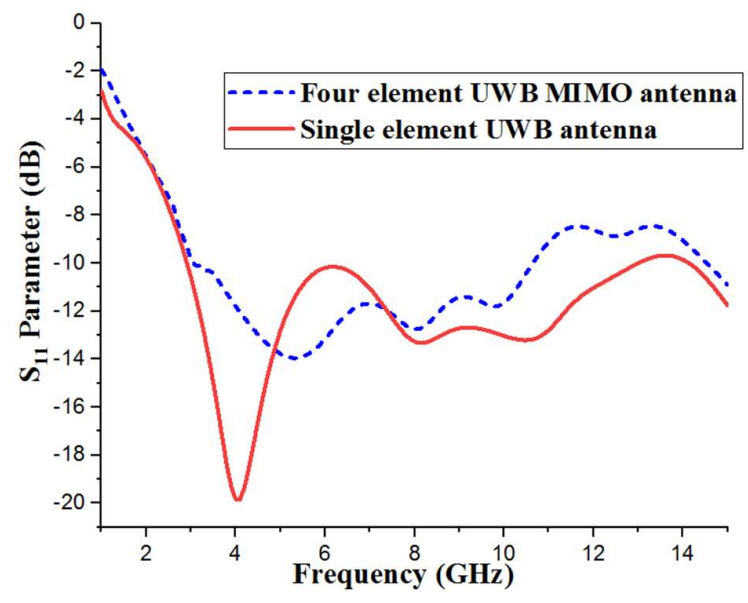

Figure 3. Simulated plot of return loss 


\subsection{Isolation}

The main challenge in construction of UWB MIMO technology is to increase the number of elements in antenna array with high isolation and without introduction of any decoupling circuits. The isolation of the proposed antenna isgreater than $23 \mathrm{~dB}$ as observed over UWB band.

\subsection{Fabricated antenna}

The proposed MIMO antenna is fabricated on a low cost FR4 substrate with the thickness of $1.6 \mathrm{~mm}$ which is shown in Figure 4. The fabricated antenna is testedforreturn loss and isolation parameters using Rohde and Schwarz vector network analyzer as shown in Figure 5. During measurement, one port is excited and other ports are matched with $50-\Omega$ load impedance. Figure 6 , depicts the comparison plot of simulated and measured results of return loss in which the antenna covers the UWB band of 3.1-10.6 GHz with $\mathrm{S}_{11}<-10 \mathrm{~dB}$ and it can be observed that the measured S-parameters are very well matching with the simulation results.

It can be observed from Figure 7, that the antenna has a high port isolation of $>23 \mathrm{~dB}$ over the entire UWB spectrum. The performance of proposed antenna in terms of gain and radiation pattern are tested using Anechoic chamber which is shown is Figure 8. The summary of the performance of the proposed antenna with the existing UWB MIMO antennas is tabulated in Table 2. It can be observed that the proposed antenna is better in terms of size, simplicity and isolation.

Table 2. Comparison of proposed MIMO antenna with existing structures

\begin{tabular}{ccccccc}
\hline Ref. & $\begin{array}{c}\text { No. of } \\
\text { elements }\end{array}$ & $\begin{array}{c}\text { Bandwidth } \\
(\mathrm{GHz})\end{array}$ & Size $(\lambda \times \lambda)$ & $\begin{array}{c}\text { Complexity } \\
(\text { Yes/No })\end{array}$ & $\begin{array}{c}\text { Decouplers } \\
(\text { Yes/No })\end{array}$ & $\mathrm{S}_{\mathrm{ij}}{ }^{*}(\mathrm{~dB})$ \\
\hline$[1]$ & 2 & $3.1-10.9$ & $0.4 \times 0.4$ & Yes & Yes & $>15$ \\
{$[2]$} & 2 & $3.1-5$ & $0.34 \times 0.16$ & Yes & Yes & $>22$ \\
{$[3]$} & 2 & $2.4-9.2$ & $0.32 \times 0.32$ & Yes & Yes & $>20$ \\
{$[4]$} & 2 & $3.4-12$ & $0.45 \times 0.45$ & Yes & Yes & $>15$ \\
{$[5]$} & 2 & $2.87-10.4$ & $0.28 \times 0.25$ & Yes & Yes & $>20$ \\
{$[6]$} & 2 & $4.2-9$ & $0.49 \times 0.53$ & Yes & Yes & $>16$ \\
{$[7]$} & 2 & $3.1-10.6$ & $0.22 \times 0.26$ & Yes & Yes & $>18$ \\
{$[8]$} & 4 & $3-10.6$ & $0.6 \times 0.5$ & Yes & Yes & $>20$ \\
{$[9]$} & 2 & $2.83-10.18$ & $0.5 \times 0.3$ & Yes & Yes & $>15$ \\
{$[10]$} & 2 & $3-11.5$ & $0.48 \times 0.28$ & Yes & No & $>15$ \\
{$[11]$} & 1 & $4.5-11.8$ & $1 \times 0.7$ & No & No & Nil \\
{$[12]$} & 1 & $3-14$ & $0.3 \times 0.3$ & Yes & No & Nil \\
{$[13]$} & 2 & $2.41-2.46$ & $0.96 \times 1$ & Yes & Yes & $>27$ \\
{$[14]$} & 2 & $2.2-2.9$ & $0.51 \times 0.58$ & Yes & No & $>20$ \\
Proposed & 4 & $3.1-10.6$ & $0.4 \times 0.4$ & No & No & $>23$ \\
\hline $\mathrm{S}_{\mathrm{ij}}$ is the isolation between the ith antenna element and j ${ }^{\text {th }}$ antenna & &
\end{tabular}

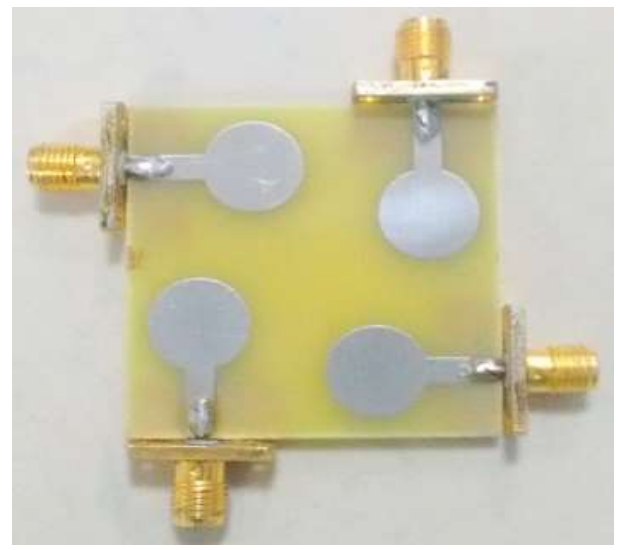

(a)

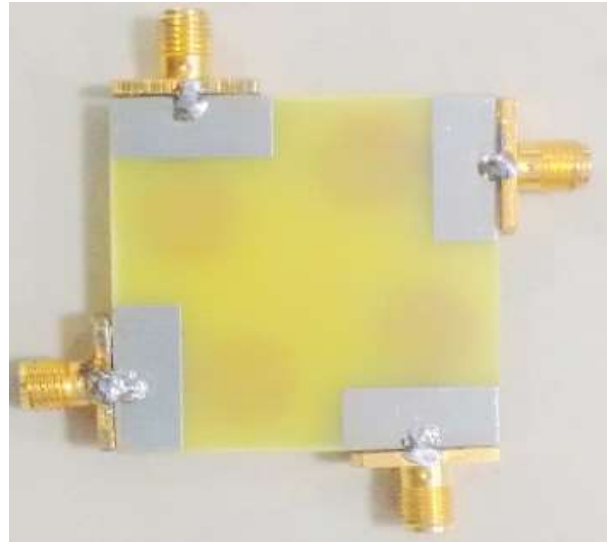

(b)

Figure 4. (a) Front view of proposed antenna and (b) Back view of proposed antenna 


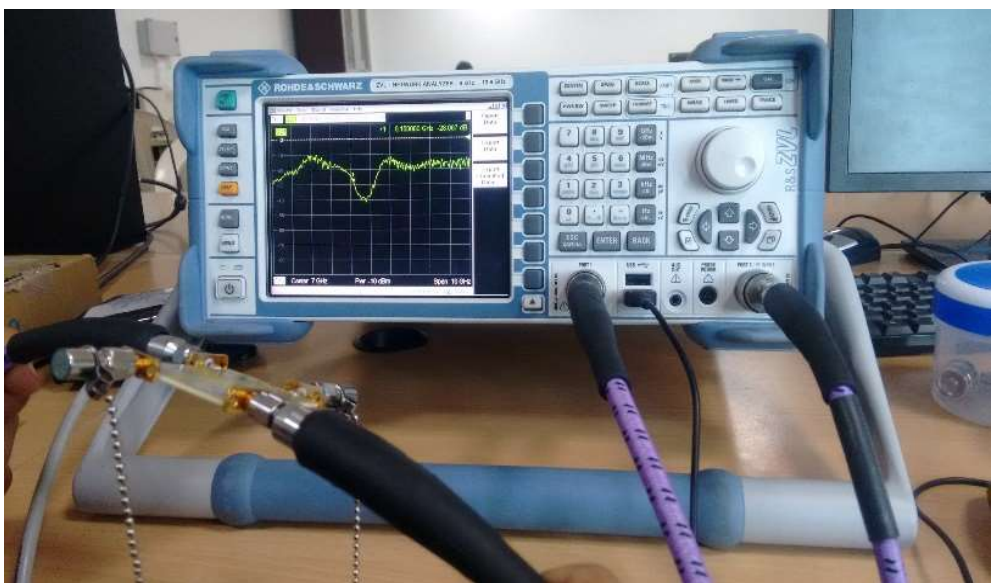

Figure 5. Measurement of isolation using vector network analyzer

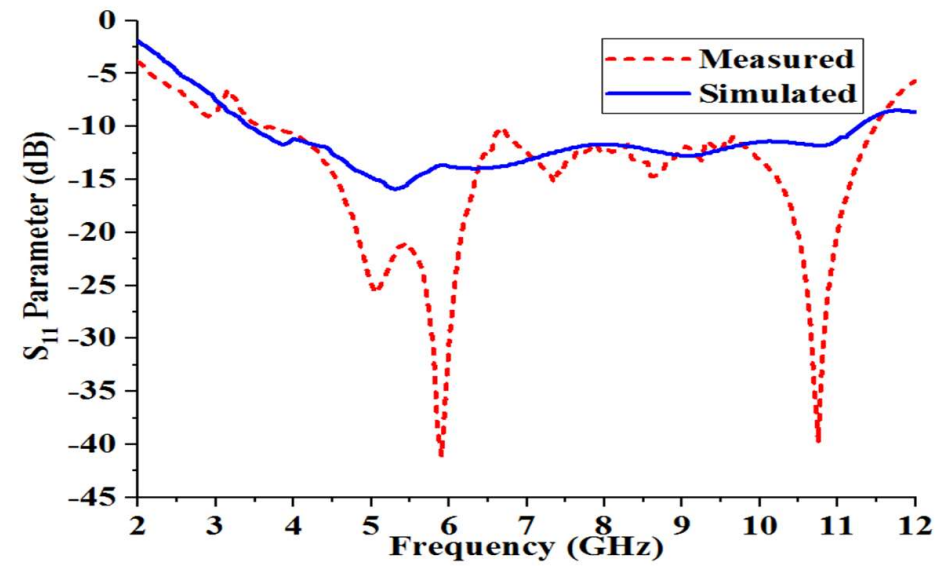

Figure 6. Simulated and measured results of return loss

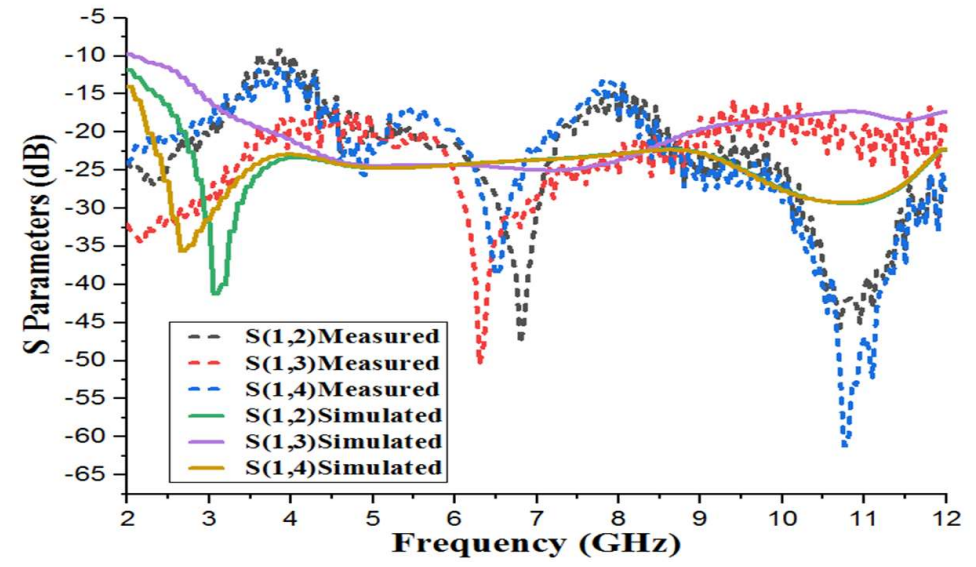

Figure 7 (a). Simulated and measured results of $S(1,2), S(1,3)$ and $S(1,4)$ 


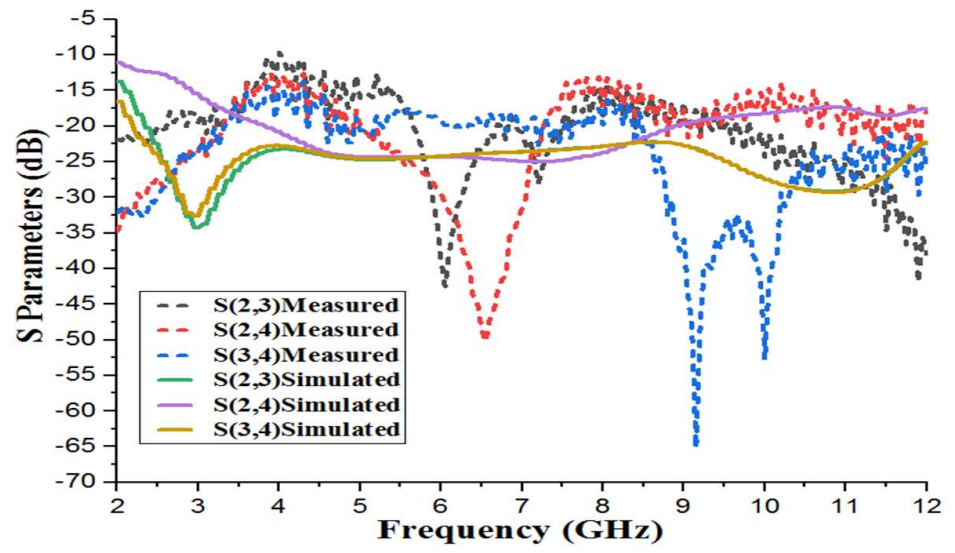

Figure 7 (b). Simulated and measured results of $\mathrm{S}(2,3), \mathrm{S}(2,4)$ and $\mathrm{S}(3,4)$

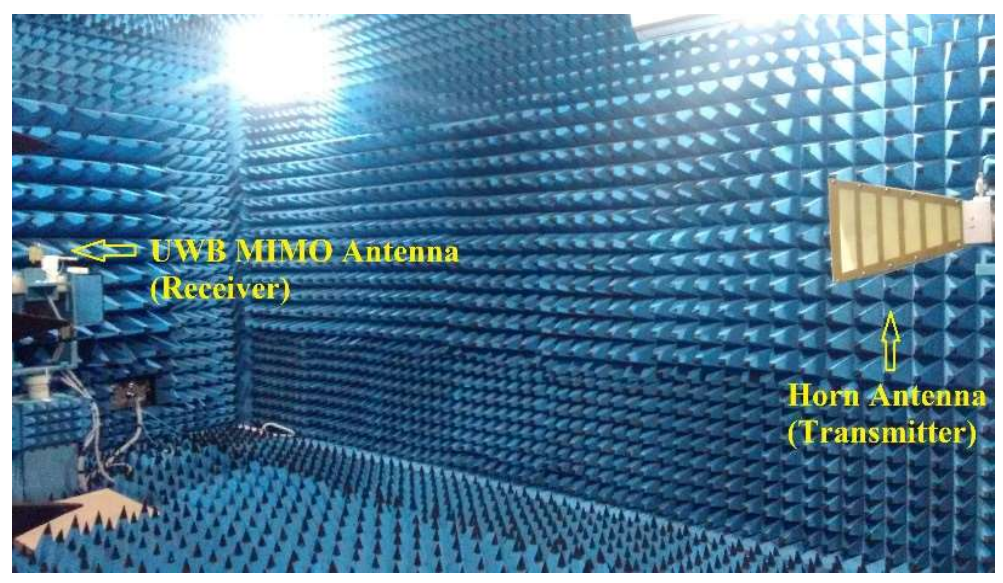

Figure 8. Measurement of gain and radiation pattern in ananechoic chamber

\subsection{Peak gain}

The peak gain of the proposed antenna is $3.1 \mathrm{dBiat} 9.9 \mathrm{GHz}$ and the gain varies from $-2.3 \mathrm{dBi}$ to $3.1 \mathrm{dBi}$ over the UWB spectrum as shown in Figure 9.

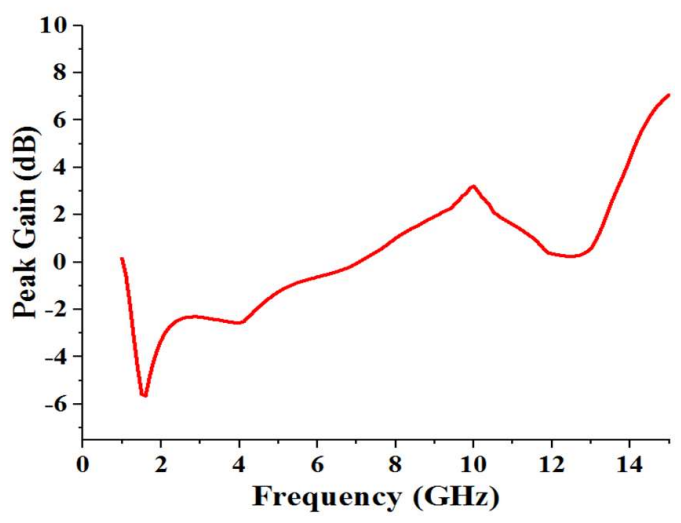

Figure 9. Peak gain plot 


\subsection{Radiation pattern}

In Figure 10 (a) to Figure 10 (c), the radiation patterns of the proposed antenna at $x z$ and $y z$ planes are investigated at $3.3 \mathrm{GHz}, 5.5 \mathrm{GHz}$ and $7.5 \mathrm{GHz}$, respectively. It can be seen that the antenna exhibits omni directional radiation pattern at $x z$ plane and a figure of eight pattern in the $y z$ plane. The radiation patterns are stable at lower, middle and higher frequencies ensuring good UWB performance.

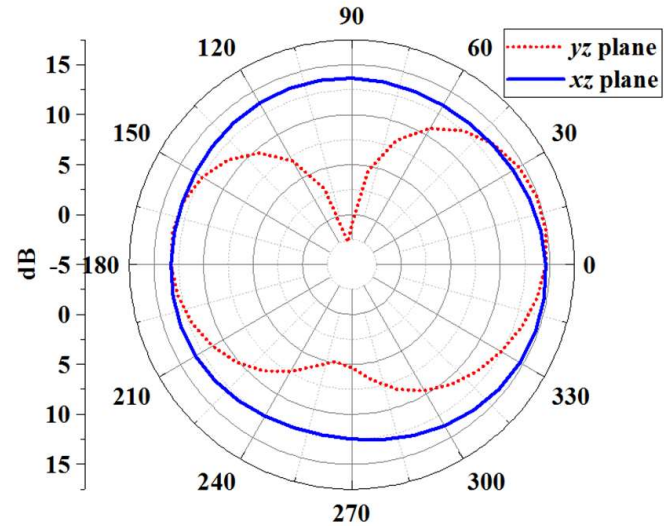

Figure 10 (a). Radiation Pattern at $3.3 \mathrm{GHz}$

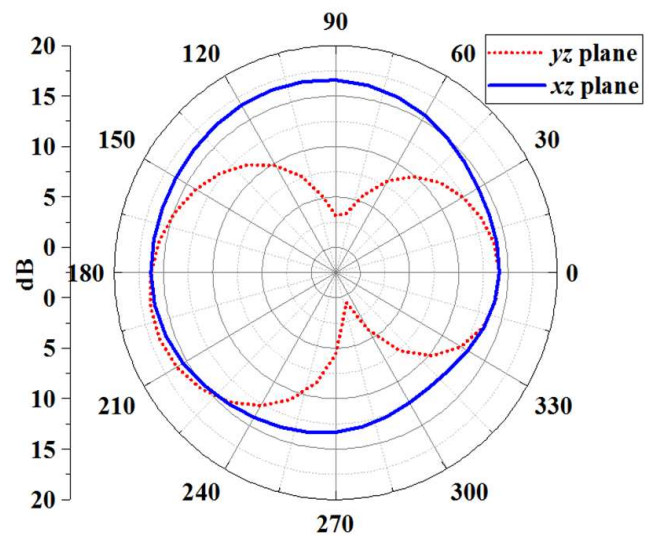

Figure 10 (b). Radiation Pattern at $5.5 \mathrm{GHz}$

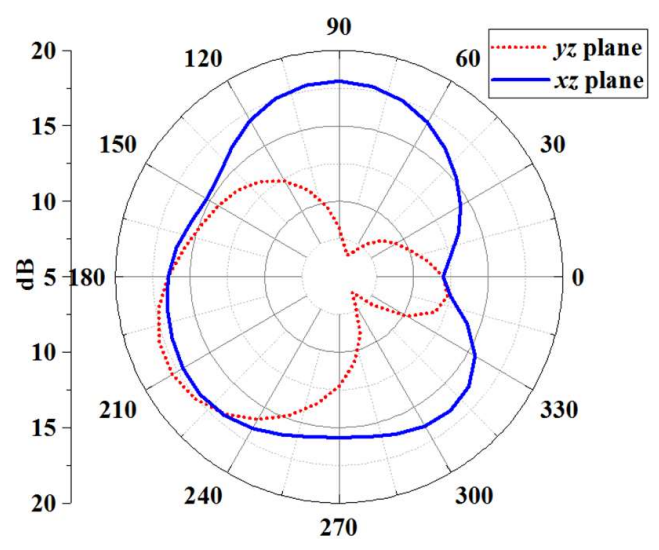

Figure 10 (c). Radiation Pattern at $7.5 \mathrm{GHz}$

\section{CONCLUSION}

A compact, cost - efficient UWB MIMO monopole antenna has been designed and investigated. The antenna has $-10 \mathrm{~dB}$ impedance bandwidth from 3.1-10.6 GHz. The proposed antenna isdevoid of decoupling circuits and has high isolation of $>23 \mathrm{~dB}$ with stable radiation patterns within the operating band. It has a very compact size of $40 \times 40 \mathrm{~mm}$ and it can be scalable to many number of elements in an antenna array which would be utilized for future $5 \mathrm{G}$ communication systems.

\section{ACKNOWLEDGEMENTS}

The authors would like to thank the institute of IIITDM Kancheepuram and VIT University, Chennai for providing the Vector network analyzer and Anechoic chamber, respectively for testing of antenna. 


\section{REFERENCES}

[1] M. Gulam Nabi Alsath and Malathi Kanagasabai, "Compact UWB monopole antenna for automotive communications," IEEE Transactions on Antennas and Propagation, vol. 63(9), pp. 4204-4208, 2015.

[2] S. Zhang and G. Pedersen, "Mutual coupling reduction for UWB MIMO antennas with a wideband neutralization line," IEEE Antennas Wireless Propag., Lett., vol. 15(5), pp. 166-169, 2015.

[3] Inderpreet Kaur Sokhi, R. Ramesh, and Usha Kiran, "Design of UWB-MIMO Antenna for Wireless Applications," IEEE WiSPNET 2016 conference, 2016.

[4] Jianfeng Zhu, Botao Feng, Biao Peng, Shufang Li, and Li Deng, "Compact CPW UWB diversity slot antenna with dual band-notched characteristics," Microwave and Optical Technology Letters, vol. 58(4), pp. 989-994, 2016.

[5] Minal Dhanvijay, Anuradha Pattekar, and Rajiv Kumar Gupta, "Compact Circular Ring Shaped Monopole UWB MIMO Antenna," 2017 IEEE 3rd International Conference on Sensing, Signal Processing and Security, 2017.

[6] Ankit Kumar Verma, R. Nakkeeran, and Rigvendra Kumar Vardhan, "Design of $2 \times 2$ single sided wrench shaped UWB MIMO antenna with high isolation," 2016 International Conference on Circuit, Power and Computing Technologies [ICCPCT], 2016.

[7] Chao-Ming Luo, Jing-Song Hong, and Lin-Lin Zhong, "Isolation Enhancement of a Very Compact UWB-MIMO Slot Antenna with Two Defected Ground Structures," IEEE Antennas and Wireless Propag., Lett., vol. 14(4), pp. 1766-1769, 2015.

[8] Ahmed A. Ibrahim, Mahmoud A. Abdalla, and ohn L. Volakis, "4 Elements UWB MIMO Antenna for Wireless Applications," Antennas and Propagation \& USNC/URSI National Radio Science Meeting, 2017.

[9] Chetan P. Bambarkar, Sukanya Kulkarni, "Design of ultra-wideband (UWB) MIMO antenna," 2017 International Conference on Intelligent Computing and Control (I2C2), 2017.

[10] Ahmed A. Ibrahim, Jan Machac, and Raed M. Shubair, "Compact UWB MIMO Antenna with Asymmetric Coplanar Strip Feeding Configuration," 2017 IEEE 28th Annual International Symposium on Personal, Indoor, and Mobile Radio Communications (PIMRC), 2017.

[11] P. Kumar, M. Tripathy, and H. P. Sinha, "Wide Band CPW Fed Slotted Microstrip Antenna," TELKOMNIKA Indonesian Journal of Electrical Engineering and Computer Science, vol. 15(1), pp. 114-119, 2015.

[12] Ammar Alhegazi, Zahriladha Zakaria, Noor Azwan Shairi, Sharif Ahmed, and Tole Sutikno, "UWB Filtenna with Electronically Reconfigurable Band Notch using Defected Microstrip Structure," TELKOMNIKA Indonesian Journal of Electrical Engineering and Computer Science, vol. 8(2), pp. 302-307, 2017.

[13] Charles MacWright Thomas, Huda A. Majid, Zuhairiah Zainal Abidin, Samsul Haimi Dahlan, Mohamad Kamal A. Rahim, and Raimi Dewan, "A Study on V-Shaped Microstrip Patch MIMO Antenna," TELKOMNIKA Indonesian Journal of Electrical Engineering and Computer Science, vol. 5(3), pp. 606-611, 2017.

[14] S. Salihah, M. H. Jamaluddin, R. Selvaraju, and M. N. Hafiz, "A MIMO H-shape Dielectric Resonator Antenna for 4G Applications," TELKOMNIKA Indonesian Journal of Electrical Engineering and Computer Science, vol. 10(2), pp. 648-653, 2018.

Int. J. of Adv. in Appl. Sci. Vol. 8, No. 3, September 2019: 243 - 250 